\title{
EVIDENCES OF RELATIONSHIP INDICATED BY THE VENATION OF THE FORE. WINGS OF CERTAIN INSECTS, WITH ESPECIAL REFERENCE TO THE HEMIPTERA-HOMOPTERA.
}

\author{
By G. C. Crampton, Ph. D.
}

Massachusetts Agricultural College, Amherst, Mass.

In the August issue of Psyche for 1921 (Vol. 28, p..116) Mr. F. Muir offers a criticism of certain views proposed by me concerning the origin and relationships of the Hemiptera, and since Mr. Muir's criticism is apparently based upon a complete misunderstanding of my contentions concerning the interrelationships of the insectan orders in general, and the Hemiptera and Homoptera in particular, I would take this opportunity of correcting the mistaken impression given by Mr. Muir in his criticism. It is necessary first, however, to clearly understand the interrelationships of the lower forms and allied insects, before taking up the discussion of the phylogenetic development of the Hemiptera and Homoptera, and on this account I would postpone the discussion of Mr. Muir's criticism until the evidence of relationship to be gained from a study of the venation of the fore wings has been presented.

The discussion of the evidences of relationship in the different orders of insects indicated by a study of the venation of the fore wings has been taken up in the present paper because the wing veins are practically the only structural details preserved in a condition suitable for a comparative study in the fossil precursors of living insects, and because the evidence of the wing venation is apparently the only evidence of relationship which recent students of insect phylogeny deem worthy of their consideration! So far as possible, however, I have used the evidence of the wing veins to corroberate the evidences of relationship drawn from the study of numerous other structures of the body as well, thereby obviating the danger of being deceived by convergent development-as might be the case if one were to depend upon the evidence of one set of structures, such as the wing veins, alone. 
The anatomy of the body in general in the Plecoptera indicates that they are among the most important of the living forms which have departed but little from the condition typical, in many respects, of the ancestors of the Orthoptera-like insects, and the higher orders. The venation of the fore wings of recent Plecoptera, however, does not furnish a particularly favorable basis of comparison in attempting to determine the paths of development followed in the evolution of the higher orders of insects, while the venation of the Protorthoptera in particular, and in some respects that of the Protoblattids, (Propalæoptera) Hadentomoids, (Proplatyptera) Megasecoptera etc., as well, apparently furnish certain servicable clews for tracing the origin of some of the developmental (evolutionary) tendencies exhibited in the wing venation of certain of the higher orders of insects.

Since the Protorthoptera appear to be as important as any of the fossil forms suggestive of the precursors of the higher insects, it is of some interest to establish as closely as possible the types ancestral to the Protorthoptera. Handlirsch apparently derives the Protorthoptera directly from the Palæodictyoptera (or from the Synarmogoidea, which he derived from the Palæodictyoptera); but a comparison of the wings of such a Protorthopteron as Spaniodera ambulans, or even the Protorthopteron shown in Fig. 30, with the Protoblattid shown in Fig. 32, would indicate that the Protoblattids are intermediate between the Protorthoptera and the Palæodictyoptera. In the forewings of the lower Protorthoptera and in certain Protoblattids, the anal veins are numerous, and in the hind wings of certain Protorthoptera there occurs an anal fan very suggestive of that found in many Protoblattids. The character of the cubital vein with its numerous oblique branches (cubital bars) and its rather wide extent in the posterior portion of the fore wing, is strikingly similar in both Protorthoptera and Protoblattids, and the nature and extent of the subcostal bars, or veinlets extending from the subcostal vein to the anterior margin of the wing, are much alike in both groups of insects (Protorthoptera and Protoblattids). When the more primitive 
representatives of the Protorthoptera are compared with certain Protoblattids, it may readily be seen that the branches of the median and radial veins are also much the same in both groups of insects, so that the Protoblattid types of wings may be regarded as representing as nearly as any known forms, the precursors of the Protorthopterous types of wings; and the Protoblattids serve to connect the Protorthoptera with the Palæodictyoptera. I do not believe that the Protoblattids themselves are to be derived directly from the Palæodictyoptera, however, but their ancestors were possibly intermediate between the Palæodictyoptera and the ancestors of the Synarmogoids; and the Protorthoptera possibly sprang separately from the same stock, although the Protorthopterous and Protoblattid lines of descent apparently merge as we trace them back to their common stem, so far as the evidence of the wing veins would indicate.

In the reduction of the anals, the shortening of the cubital bars, and the reduction of media to two branches, the fore wing of the Hadentomoid shown in Fig. 10 presents many features suggestive of a rather close relationship with the Protorthoptera, such as the ones shown in Figs. 28 or 26, and the nature of the radius and subcosta is quite similar to that of certain other Protorthoptera. On the whole, however, the type of Hadentomoid wing shown in Fig. 10 might more readily be derived from the type of Protoblattid wing shown in Fig. 12, and it is quite possible that the line of development of the Hadentomoids arose from ancestors anatomically intermediate between the Protoblattids and the Protorthoptera very near the point where these two lines of descent began to diverge from their common Protoblattid-like forebears. The Hadentomoid type of venation is a very important one in suggesting a possible starting point in the the development of the types of venation occuring in the Embiids and their allies, as will be shown later.

The character of the anal, subcostal and cubital veins of the Mixotermitoid fore wing shown in Fig. 25, is very suggestive of both Hadentomoids (Fig. 10) and Protorthoptera (Fig. 28), and the character of the median vein is somewhat suggestive of 
that of certain Protorthoptera (Fig. 9), while the branching of the radial vein is somewhat suggestive of the condition occurring in other Protorthoptera-although the nature of the median and radial veins in the Mixotermitoids is much more suggestive of the Palæodictyoptera. The ancestors of the Mixotermitoids were possibly intermediate between those of the Hadentomoids and those of the Protorthoptera, though the Mixotermitoid type apparently harks back to the Palæodictyoptera in many respects.

In the general character of the anals and the cubital veins, and more strikingly in the nature of the branching of the median vein, the fore wing of the Hapalopteroid insect shown in Fig. 6 approaches the Protorthopteron type (Fig. 9) more closely than any other, so far as I am aware, and the precursors of the Hapaloteroids are doubtless to be sought among the Protorthoptera or their forebears. I formerly adopted Handlirsch's suggestion that the Hapalopteroids were very like the ancestors of the Plecoptera; but a closer examination of the venation of the Hapalopteroid wings would not bear out this assumption.

The more primitive types of forewing venation in the Plecoptera, such as that of Eusthenia shown in Fig. 13, apparently hark back to a Protoblattid type resembling in some respects the one shown in Fig. 12, in the nature of the cubital and anal veins; and the anal fan in the hind wing of Eusthenia is suggestive of the anal fan of the Protoblattid hind wing. On the other hand, I find much in the venation of the Plecoptera which is suggestive of a rather close relationship to the Protorthoptera, and an even closer relationship to the Hadentomoids, particularly in the nature of the branching of media and radius in the fore wing, as may be seen by comparing Fig. 11 with Fig. 10. Furthermore, if we compare the fore wing of the Plecopteron shown in Fig. 11 with the fore wing of the Embiid shown in Fig 8, the branching. of cubitus, media and radius is strikingly similar, and the evidence of the venation is therefore in harmony with that drawn from the study of other structures of the body indicating a close relationship between the Embiids and the Plecoptera-and if the Embiids are to be derived from ancestors resembling the Haden- 
tomoids and Protorthoptera in many respects, their near relatives, the Plecoptera should also be derived from ancestors resembling the Hadentomoids and Protorthoptera in many respects. It is quite possible that the line of development of the Plecoptera branched off from the common Protoblattid- Protorthopteron stem very near the point of origin of the Hadentomoid line of descent, or paralleled these lines very closely and the Plecoptera thus inherited characters found in all three of these groups (Protoblattids, Protorthoptera and Hadentomoids) from the common ancestors which combined all of their common characters in themselves.

As was mentioned above, the Embiid types of fore wings (Fig. 8 and 7) could be readily derived from precursors resembling the Hadentomoids (Fig. 10); but the Embiid types likewise approach very closely to the Protorthopteron types of venation, as one may see by comparing the anal, cubital, and median veins of the Embiid shown in Fig. 8, with these veins in the Protorthoptera shown in Figs. 26 and 28. The second and third branches of radius have begun to coalesce in the Protorthopteron shown in Fig. 26, thus indicating a tendency toward the further coalescence of these veins which has reached completion in the insect shown in Fig. 8; and in the Protorthopteron shown in Fig. 4, the second and third branches of radius coalesce and the fourth and fifth also unite, as is the case with the Embiid shown in Fig. 7. Furthermore, the tendency for all of the branches of media to coalesce exhibited by the Embiid shown in Fig. 7, also occurs in certain Protorthoptera, such, for example, as the one shown in Fig. 30, in which the media consists of but a single branch. From the foregoing facts, it is evident that the tendencies exhibited by the veins of the Embiids could be traced back to Protorthopteron predecessors quite readily. On the other hand, the character of the anals, cubitus, media, radius and subcosta of the Embiids shown in Figs. 8 and 7 is strikingly similar to the branching of these veins in the Hadentomoid insect shown in Fig. 10, and I am convinced that the ancestors of the Embiids must have resembled both the Hadentomoids and the Protorthoptera in many respects. The general anatomy of the 
Psocids such as Embidopsocus, for example, suggests a very close relationship between the Psocids and Embiids, and since the Psocids were apparently derived from Protorthoptera-like ancestors (as will be presently discussed) it is to be expected that their near relatives, the Embiids, would also be derived from Protorthoptera-like ancestors, so that in indicating an ancestry for the Embiids anatomically intermediate batween the Hadentomoids and Protorthoptera, the evidence of the wing venation is quite in harmony with that from other sources as well.

The venation of the Psocid wing shown in Fig. 1 is so similar to that of the Zorapteron shown in Fig. 3, that both were evidently derived from the same source, and what applies to one applies to the other as well. The Psocid and Zorapteron wings shown in Figs. 3 and 1 could readily be derived from the Embiid type of fore wing shown in Fig 7 (as is indicated in the hypothetical intermediate condition shown in Fig. 5)* in the following way. The second branch of cubitus of Fig. 7 might become more vertical, while vein $\mathrm{M}$, which arises from $\mathrm{M}+\mathrm{Cu}$ and coalesces for a short distance with Rs. in Fig. 7, might unite with Rs further from the base of the wing thus lengthening that portion of $M$ which extends between $\mathrm{M}+\mathrm{Cu}$ and Rs, as in Fig. 3. R2+3 of the radial sector, Rs, bends upward toward $R_{1}$ in Fig. 7 , and if $\mathrm{R} 4+5$ were to unite with it to form a single branched Rs bending forward to meet $R_{1}$, the condition exhibited by Rs in Fig. 3 would be produced. A deposition of chitin and pigment in the space between $\mathrm{Sc}$ and $\mathrm{R}_{1}$ (as indicated in Fig. 5) would produce a pterostigma such as the one labeled "ps" in Figs. 1 and 3. Judging from the same developmental tendencies found in the Psocids, Zoraptera, and Embiids, it would appear that all three were derived from a common ancestral source, and many of the genes, determinants, or factors occurring in this common source were inherited by the three derived groups, although they were naturally slightly modified by other factors in the derived groups, as would be expected. As is pointed out in the next paragraph, the ancestors of the Psocids were apparently very similar to the Protorthoptera, and since the Psocids, Zoraptera

*The figure in the left hand column between Figs. 3 and 7 is Fig 5 . The label was lost from this figure, having been pasted on too insecurely. 
and Embiids apparenty sprang from the same source, it is very probable that their common ancestors were very like the Protorthoptera in many respects.

That the fore wing of a Psocid could be readily derived from a Protorthopteron prototype may be seen by comparing the fore wing of the Psocid shown in Fig. 2 with that of the Protorthopteron shown in Fig. 4, since the venation of the two wings is strikingly similar, and the Protorthopteron type is evidently the more primitive one, since it is one of an older and lower group, and the branching of the veins in general begins nearer the base of the wing - which is usually a more primitive character than for the branches to come off nearer the apex, since the latter usually indicates a degree of coalescence, and hence a specialization, in the veins. The three anal veins are much alike in Figs. 2 and 4, and the forking of the cubitus in the Protorthopteron shown in Fig. 4 (or better still in the Protorthopteron shown in Fig. 26) is strikingly like that of the Psocid shown in Fig. 2. The three branches of media, and the two branches of $\mathrm{Rs}$ are also strikingly similar in the insects shown in Figs. 4 and 2, and the nature of the first branch of radius and the subcostal vein is much the same in both. The Psocids and Protorthoptera thus apparently have many developmental tendencies in common, and probably inherited them from a common ancestry which was very like certain Protorthoptera in may respects, and as was mentioned above, the ancestors of the Zoraptera and Embiids probably also resembled the Protorthoptera in many respects. As will be shown in the next paragrpah, the Psocids and Hemiptera-Homoptera have so much in common, that they also in all probability were derived from the same type of ancestors which must likewise have resembled the Protorthoptera in many respects, although the ancestors of the Homoptera in all probability resembled the Protoblattids as well, and the "roots" of the Homopteron stem apparently strike somewhat more deeply down into the Palæodictyopterous types.

The peculiar bulging antefrontal region of the head incorrectly called the "clypeus" in Cicadid Homoptera and Psocids, the peculiar lengthening of the segments of the antennæ, which, so 
far as I am aware, occurs exactly in that fashion only in the Homoptera and Psocids, the nature of the thoracic terga and wing bases, the nature of the tarsal segmentation, and other regions of the leg, the nature of the abdominal segments in general, the segments of certain males and the ovipositors of certain females in particular, and many other features too numerous to mention at this point, all clearly indicate so close a relationship between the Psocids and Homoptera, that it would be stretching the laws of probability and chance far beyond the breaking point to claim that the marked similarity in all of these structures from all parts of the body, and extending through a wide-ranging series of forms, is merey the result of "convergence," and it would be very interesting to learn from those who continually cry "convergence" whenever similarities are pointed out between the Psocids and Homoptera, just how "convergence" could be brought about in so wide a range of forms and in such a multitude of details from all parts of the body! That the many similarities in structures from other parts of the body extend to the venation of the wings as well, in the Psocids and Homoptera, is shown in the series of insects figured in Figs. 17 to 24, which includes some of the most primitive, and the most highly specialized, as well as the intermediate types of venation, in the two groups of insects. Thus, the peculiar "broken" character of the venation of the apical portion of the Psocid wing shown in Fig. 24 is paralleled by the wing of the Homopteron shown in Fig. 23, although the fore wing of the Homopteron Cercopis sp., figured by Handlirsch, 1909, would have been better for a comparison with the Psocid shown in Fig. 24, than is the case with the Homopteron shown in Fig. 23. The broader more primitively veined Psocid wing shown in Fig. 22 is paralleled by that of the Homopteron shown in Fig. 21, and the venation in the two is quite similar. Turning next to the intermediate type of venation shown in Fig. 18, it is quite evident that the Psocid shown in Fig. 18 is approached by the Homopteron shown in Fig. 20, especially in the character of the anals, and the branching of cubitus and media, which is strikingly similar in the two groups of insects, and there is evidently a tendency toward the formation of a pterostigma 
between the first branch of radius and the anterior margin of the wing, as well as a tendency for Rs to turn forward toward the anterior muargin of the wing. In order to make the series include as wide a range of types as possible, I have included some of the most specialized types as well, and, as one may see by comparing Figs. 17 and 19, in which radius and media are practically the only veins retained in a well develped condition, there is a marked parallelism in the more highly specialized members of the two groups, as well as in the intermediate and more primitive representatives of the Psocids and Homotera. This parallelism in a wide range of wing types, as well as in a multitude of structures from all parts of the body, can be explained only as the result of the operation of the same developmental tendencies (i.e. the expression of the presence of the same genes, determinants or factors - albeit these are modified to some extent in the derived groups by the influence of other factors) inherited from a common ancestry.

From the foregoing facts, I would conclude that the Psocids and Hemiptera-Homoptera were descended from very similar ancestors, and since the Psocids were apparently descended from ancestors closely resembling the Protorthoptera in many respects, it naturally follows that the ancestors of the Homoptera must also have resembled the Protorthoptera in many respects. The fact that the saltatorial Orthoptera, which are the modern representatives of the Protorthoptera, have likewise retained many features suggestive of affinities with the HemipteraHomoptera is also in harmony with such a derivation of the Homoptera; but there are other factors involved, which further complicate the question of the origin of the Homoptera. The primitive type of venation exhibited by the fore wing of the Homopteron Hotinus sp., figured by Handlirsch, 1909, appears to be of a lower type than that of most Protorthopterous fore wings, and suggests affinities with the Neuroptera and Protoblattids. The venation of the Homopteron Ormenis is also very suggestive of that of certain Neuroptera such as Psychopsis, particularly in the peculiar arrangement of certain small cross veins which unite end-to-end to form a paramarginal line extend- 
ing parallel to the margin (but at some distance from it) in the fore wing. The nature of the thoracic sclerites of the Homoptera would lend further weight to the view that the ancestors of the Homoptera were very like those of the Neuroptera, and the fact that many insects descended from the common Neuropteroid stem, such as the Mecoptera (and even the Siphonaptera) exhibit very similar tendencies in the specialization of their mouth-parts (which tend to lose the ligula, while the labial palpi become approximated and unite to some extent, and the maxillæ become much elongate and somewhat stilet-like) would suggest that they and the Homoptera inherited these tendencies from a common ancestry. Furthermore, the fore wings of certain primitive Trichoptera and Mecoptera, which were derived from a common Neuropteroid stem, show undoubted affinities with certain types of Homopterous fore wings, and lend further weight to the supposition that the ancestors of the Homoptera resembled those of the Neuropteroid insects in many respects. Thus, the Trichopterous fore wing shown in Fig. 27 is remarkably like that of the Homopteron shown in Fig. 29, especially in the character of the anal and cubital veins; and the other veins of the wing are also of much the same type in the two wings under consideration. All of these facts, which indicate that the ancestors of the Homoptera and Neuroptera were very closely related, are in harmony with the fact that the Homoptera and Psocids are also very closely related, since the Psocids themselves are clearly related to the Neuroptera, and their line of development apparently merges with that of the Neuroptera near its point of origin, thereby involving the line of develpoment of the Homoptera with that of the Neuroptera through their mutual relationship to the Psocids, as well as through the more direct affinities of the Homoptera themselves with the Neuropteroid insects. I have therefore maintained that the ancestors of the Homoptera were intermediate between those of the Psocids and those of the Neuroptera, and the present study of the fore wing venation would uphold the correctness of this view.

If one compares the wing of a Neuropteron such as the one shown in Fig. 34, with the wing of a Protoblattid such as the one 
shown in Fig. 32, there is a pronounced similarity between the two types of wings, especially in the nature of the anal veins, and the cubital and subcostal bars. The character of the median vein is also quite similar in both, although the radial veins are not quite so much alike in the two insects. While there is considerable evidence pointing to the Protoblattids as the probable precursors of certain primitive types of Neuropterous wings, some of the Neuropterous types, on the other hand, have retained certain Palæodictyopterous characters which suggest that they hark back to Palæodictyoptera-like forebears. Handlirsch suggests that the Megasecoptera represent the precursors of the Neuroptera, and certain tendencies in the Megasecopterous wing, such as the tendency toward the anastomosis of the radial sector, media, and cubitus, are certainly very suggestive of similar tendencies in the wings of certain Neuroptera. I would not derive the Neuroptera directly from the Megasecoptera, however, as Handlirsch does, since the Neuropterous wings evidently partake of certain characters in common with the Protoblattids in addition to preserving certain features suggestive of the Palæodictyoptera, so that all of these lines of descent apparently either branched off near the base of the common Protorthopteron-Protoblattid stem, or they parallel each other remarkably closely as we trace them all back to their common Palæodictyoptera-like ancestors.

In the nature of the branching of its anal, cubital, and median veins, Eugereon, the supposed ancestor of the Hemiptera and Homoptera (Fig. 31) is apparently a Palæodictyopteroid insect resembling, in some respects, the Palæodictyopteron shown in Fig. 33, while in many features the wing of Eugereon is very suggestive of the Megasecopteron type. The primitive type of Homopterous wing shown in Fig. 29 is not very similar to Eugereon's wing (Fig. 31), and it would be very difficult to derive the primitive type of venation exhibited by the Homopteron Hotinus (which is more like a Neuropterous or Protoblattid type) mentioned above, from a wing such as that of Eugereon, since the latter appears to be somewhat more specialized than the venation of Hotinus. Taking all of the facts into con- 
sideration, it would appear to be more probable that instead of arising from Eugereon, the line of descent of the Homoptera arose at the base of a common Protorthopteron-Protoblattid stem, or it parallels the common Protorthopteron- Protoblattid stem very closely as we trace them all back to their common ancestors resembling the Palæodictyoptera, which gave rise to such forms as Eugereon, and the Megasecoptera.

In the nature of their mouthparts, their widely separated coxæ and broad sterna, and to some extent in the nature of their ovipositors, etc., the Thysanoptera exhibit many features suggestive of a relationship with the Hemiptera; but the venation of the Thysanoptera is too highly specialized to be of much value in determining the origin and affinities of the Hemiptera, although they do offer certain points of contact with both Hemiptera and Psocids, which would be expected if the Psocids and Hemiptera were related both to each other and to the Thysanoptera. The character of the radial and median veins which extend parallel to each other down the center of the wing of the Psocid shown in Fig. 17 is very suggestive of the character of the radius and media which also extend parallel to each other down the middle of the Thysanopteron wing shown in Fig. 15. The radial and median veins of the Orthopteron shown in Fig. 16, however, likewise extend parallel to each other down the center of the wing, and the character of the cubital vein, and the branches of the radial vein of the Orthopteron shown in Fig. 16 are even more like those of the primitive Thysanopteron shown in Fig. 14. These similarities may be taken to indicate that the Orthoptera, Psocids and Thysanoptera were all descended from Protorthoptera-like precursors, and inherited much the same tendencies from this common ancestry, although these tendencies (or the genes, determinants, or what not, which they express) were slightly modified by different factors in the different lines of development derived from this common source If the Hemiptera-Homoptera were also descended from ancestors similar to the Protorthoptera in many respects, this might also account for certain similarities between the Hemiptera-Homoptera and certain Orthoptera, which are too evident to be entirely passed over. 
The facts brought out in the foregoing discussion would indicate that the ancestors of the Hemiptera-Homoptera arose from forms anatomically intermediate between the ancestors of the Psocids and those of the Neuropteroid insects. In other words, the ancestors of the Hemiptera-Homoptera were apparently anatomically intermediate between the insects forming the common Protorthopteron-Protoblattid stem and the Megasecoptera, and their line of descent either merged with that of the Protorthopteron-Protoblattid stem and the Megasecoptera, or paralleled them extremely closely, as they all approached their common origin in an ancestral group resembling the Palæodictyoptera in many respects. The interrelationships of the primitive forms grouped about the base of the lines of descent of the Homoptera and the Neuropteroid insects is shown in the appended diagram (Text figure 1) in which the lines of descent in

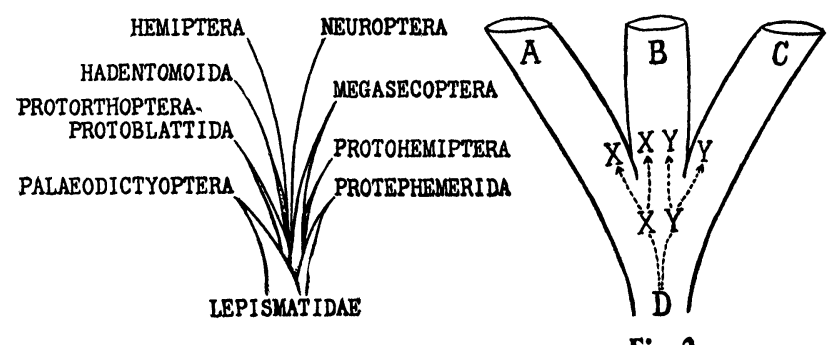

Fig. 1

Fig. 2

question are represented as though branching off in different directions, since this method apparently is more in accord with the facts of a complicated interrelationship between these groups of insects than is the case when one attempts to represent their lines of descent by means of a dichotymously branching tree.

Having repeatedly stated that no living forms can be derived from other living forms (see footnote to page 148 of the American Naturalist, Vol. LIII, 1919, etc.) and since this fact is so widely accepted as to be more of the nature of a truism, it hardly seemed necessary to waste energy and space by repeating this utterly obvious fact every time a living insect was compared with a 
another living insect belonging to a more primitive group; and on this account it is amazing that Mr. Muir should accuse me of deriving living Psyllids from living Psocids especially since I definitely state in a paragraph which he quotes, that the lines of descent of the Homoptera, Thysanoptera, Psocids Hymenoptera and related forms "apparently arose from ancestors intermediate between the Zoraptera (with the Isoptera) on the one side, and the Coleoptera (with the Dermaptera) on the other." In other words, the ancestors of the Homoptera, Psocida, Hymenoptera, etc., were very similar to the Protorthopteron-like and Protoblattid-like ancestors of the Zoraptera and Coleoptera. This is surely a very different matter from claiming that the Homoptera were descended from living Psocids! I have always been careful to state that the Psocids were in many respects very like the ancestors of the Homoptera, just as the chimpanzees are in many respects very like the ancestors of man (i.e. the Pithecanthropus-like forms), yet such a statement by no means implies that men were descended from living chimpanzees-and the same principle holds true in the comparison of the Homoptera with the Psocids, abeit the groups compared in the latter case belong to different orders instead of belonging to different families of the same order, and the differences are naturally somewhat greater in the one instance than in the other. The idea which I intended to convey is that the Psocids and Homoptera are very closely related (i.e. they have both inherited many tendencies in common which cause their lines of development to parallel each other quite closely) and since the Psocids have evidently departed less than the Homoptera have from the common ancestral types, the ancestral features which they have preserved in a less modified condition, enable us to form some conception of the character of these features in the ancestors of the Homoptera.

Starting with the false assumption that I would derive living Homoptera from living Psocids (an obvious impossibility), Mr. Muir proceeds to a second equally false assumption that I would derive all Homoptera from living Psocids by way of the highly specialized recent family Psyllidæ, simply because I 
chanced to use a fore wing of an insect belonging to the genus Psylla to illustrate the operation of the same developmental tendencies in the evolution of the wing veins throughout the orders Homoptera and Psocida. The wing type exhibited by Psylla, however, is but one of a wide-ranging series of forms (a few of which are shown in Figs. 17 to 24), extending from the lower Psocids and Homoptera to the higher specialized members of the two groups, in which the developmental tendencies operative in directing the evolution of the various types of venation in the Psocid wings are closely paralleled throughout the series by similar developmental tendencies operating in the evolution of the various types of Homopterous wings. In other words, the same genes, determinants or factors were in many cases inherited in both groups from a common ancestry, although they were naturally modified somewhat by different factors in the two distinct orders of insects. This again is a very different matter from claiming that all Homoptera were descended from the highly specialized recent Homopterous family Psyllidæ, and I am at a loss to understand how Mr. Muir could have so completely misconstrued my meaning in this matter.

As a final and culminating false assumption, Mr. Muir implies that I "believe that new orders arise as hybrids from the crossing of individuals belonging to different orders" of insects! The fact that every student of evolution knows full well that the offspring of crosses between different species are generally sterile, and those between different genera are almost invariably so (save in the plant kingdom) should have deterred Mr. Muir from making this curious mistake. However, lest others be misled by Mr. Muir's implication, I would endeavor to indicate graphically by means the diagram shown in Text figure 2 , how a third order of insects may partake of characters present in two other orders, without being the result of the crossing of members of the other two orders possessing characters in common with it. I have drawn a similar diagram, and explained it, in an article published in the Fiftieth Annual Report of the Ent. Society of Ontario for 1919; and in order to use the same concrete examples, let us suppose by way of illustration that "A" in Text figure 2 
represents the line of development of the higher Crustacea (Isopods, etc.), while " $\mathrm{B}$ " represents the line of development of the lower Insecta, and " $\mathrm{C}$ " represents the line of development of the "Myriopoda", all of which were derived from a common ancestral group "D", some of whose members contained the factor or group of factors " $x$ ", which produces a flat head with mandibles extending up the sides of the head to a point behind the eyes (as the insect Lepisma, and the isopod Asellus) while others of the ancestral group contained the factor "y," which produces a pyriform head with cryptognathous (endognathous) mouthparts (as in the insect Campodea and the "myriopod" Scolopendrella). It should be quite evident from the diagram in Text figure 2 that certain insects in " $B$ " could inherit the characters " $x$ " (flat head with huge mandibles) from the "side" of, or in common with, certain higher Crustacea in "A", having inherited these tendencies or factors from the common group " $D$ ", which gave rise to both " $\mathrm{A}$ " and " $\mathrm{B}$ ", while certain other insects in " $\mathrm{B}$ " could inherit the characters " $y$ " (pyriform head with cryptognathous mouthparts) from the "side" of, or in common with certain Symphyla ("myriopods") in "C", having inherited these tendencies from the common ancestral group " $D$ ", which gave rise to both " $\mathrm{B}$ " and " $\mathrm{C}$ ", without postulating that members of " $\mathrm{A}$ ", and " $\mathrm{C}$ " must have interbred to produce these characters in " $\mathrm{B}$ ". In order to apply the same principle to the orders of insects, let us suppose that "A" represents the line of development of the Psocids, "B" that of the Hymenoptera, and "C" that of the Coleoptera, all of which were descended from ancestors resembling the Protorthoptera in many respects, which may be represented by the ancestral group " $D$ ". If " $x$ " represents the factor or factors producing colonial tendencies, while " $y$ " represents the factors producing styli-bearing ovipositors, for example, it should be readily apparent from the diagram, that some members of both Psocids ("A") and Hymenoptera ("B") could inherit tendencies toward "social" life (represented by " $x$ ") from a common source in "D", while some members of both Hymenoptera ("B") and Coleoptera ("C") could inherit their tendencies toward the development of styli-bearing ovipostors (represented by "y") 
from a common source in " $\mathrm{D}$ ", without postulating that Coleoptera with styli-bearing ovipositors mated with "socially" inclined Psocids to produce Hymenoptera possessed of these qualities, and it is difficult to understand how Mr. Muir could have arrived at such an obvious "reductio ad absurdum" in this matter.

From the foregoing discussion, it is evident that it would be impossible to accurately represent the lines of development of the various insectan orders by means of a dichotomously branching tree, since such an arrangement ignores the evident interrelationships between several orders of insects which apparently have sprung from a single ancestral group, and I know of no developmental law necessitating that all evolution in living things shall follow a dichotomously branching path. In fact, the known evidence would seem to indicate that such a method is extremely rare among insects, and it is better to make a theory to fit the facts, than to adhere to some hypothesis which is not in accord with most of the facts which one encounters in his observations. I would therefore prefer to represent the orders comprising the lines of descent of the three sections of winged insects by means of cone-like figures in which the closely interrelated orders converge to a common point of origin in each section. Of these three Pterygotan sections, the higher insects or Neuropteradelphia include the Neuropteroid super-order (Neuroptera, Hymenoptera, Mecoptera, etc.) and the Psocoid superorder (Psocids, Zoraptera, Homoptera, etc.); while the intermediate insects or Orthopteradelphia include the Orthopteroid superorder (Orthoptera, Phasmids, etc.) the Blattoid superorder (Blattids, Isoptera, Mantids, etc.) and the Plecopteroid superorder (Plecoptera, Embiids,, etc.); and the lower insects or Plectopteradelphia include the Palæodictyoptera, Odonata, Ephemerida, etc. The final assignment of certain aberrant orders of obscure affinities has not been definitely determined, but in the main, the venation of the fore wings is in agreement with the grouping of insects into superorders given on page 114 of Vol. 53 of the Canadian Entomologist for 1921. 
Abbreviations.

The Arabic subscripts indicate the branches of the veins in question, and a plus sign denotes a coalescence of veins. $\mathrm{A}=\mathrm{Anal}$ veins; at=alatenaculum; $a x=$ axillary or second anal vein; $\mathrm{Cu}=$ cubital veins; $\mathrm{M}=$ median veins; $\mathrm{pt}=$ pterostigma; $\mathrm{R}=$ radial veins; $\mathrm{R}_{\mathrm{s}}=$ radial sector; $\mathrm{S} c=$ subcostal vein.

$$
\text { Explanation of Plates I, II, and III. }
$$

All figures are of right fore wings. The primitive reticulation (alarete or archidictyon) is partially or wholly omitted in some cases as is also true of many of the cross veins.

Fig. 1.-Psocid Archipsocus recens, from Crampton, 1921, after Enderlein, 1903.

Fig. 2.-Psocid Amphientomum paradoxum, redrawn from Tillyard, 1918.

Fig. 3.-Zorapteron Zorotypus snyderi, from Crampton, 1921.

Fig. 4.-Protorthopteron Lepium elongatum, redrawn from Handlirsch, 1920.

Fig. 5.-Hypothetical stage intermediate between Fig. 7 and Fig. 3.*

Fig. 6.-Hapalopteroid Hapaloptera gracilis, redrawn from Handlirsch, 1920.

Fig. 7.-Embiid Oligotoma saundersi, from .Crampton, 1921, after Wood-Mason, 1883.

Fig. 8.-Embiid Donaconethis abyssinica redrawn from Comstock, 1918 after Enderlein, 1912.

Fig. 9.-Protorthopteron Liomopterum ornatum, redrawn from Handlirsch, 1920.

Fig. 10.-Hadentomoid Hadentomum americanum, from Crampton, 1921, after Handlirsch, 1906.

Fig. 11.-Plecopteron Zelandobius confusus, redrawn from Tillyard, 1921.

Fig. 12.-Protoblattid Asyncritus reticulatus, redrawn from Handlirsch, 1920.

Fig. 13.-Plecopteron Eusthenia spectabilis, redrawn from Comstock, 1918. 


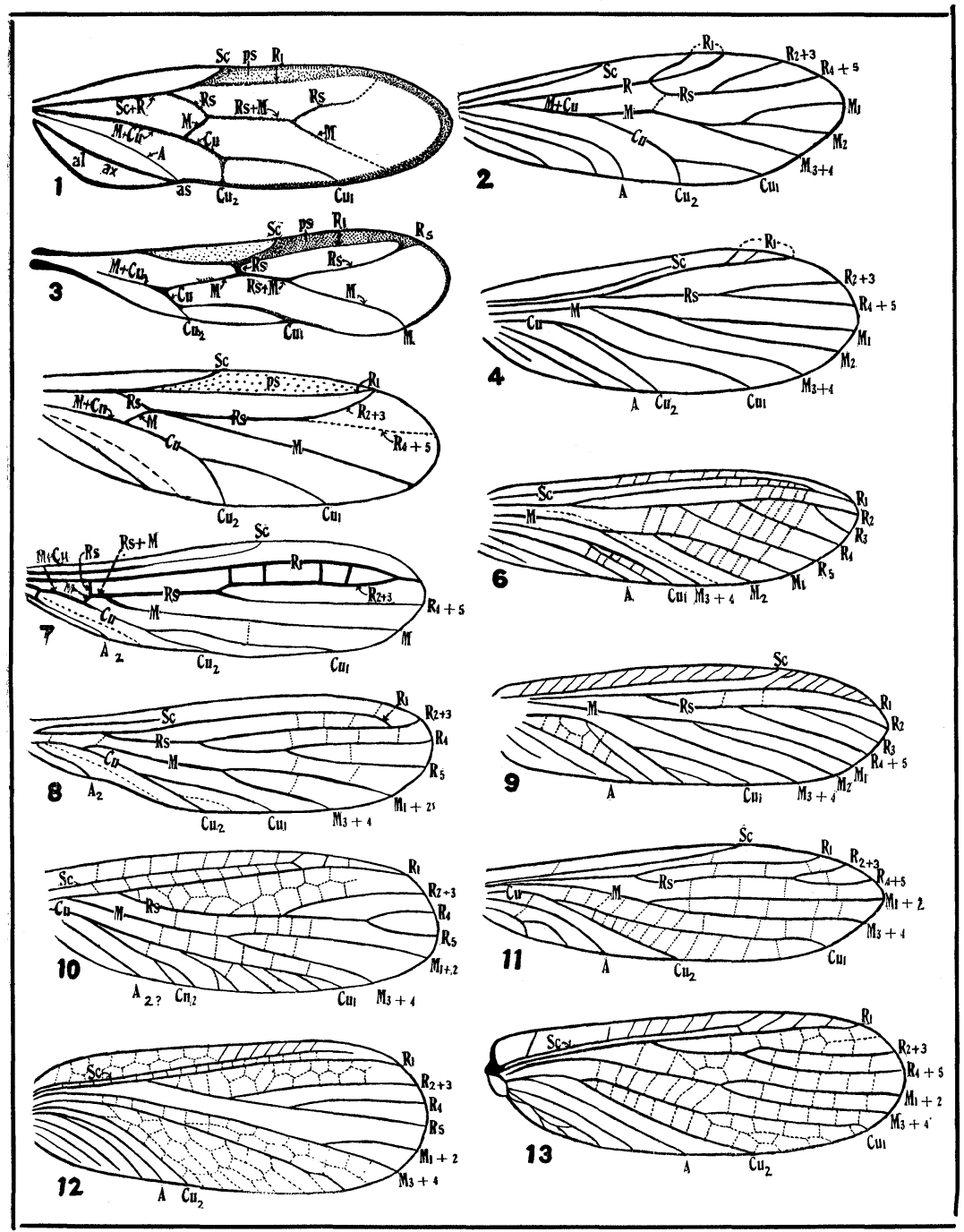

Crampton-Wings of Hemiptera-Homoptera 
Psyche, 1922.

Vol. XXIX Plate II.

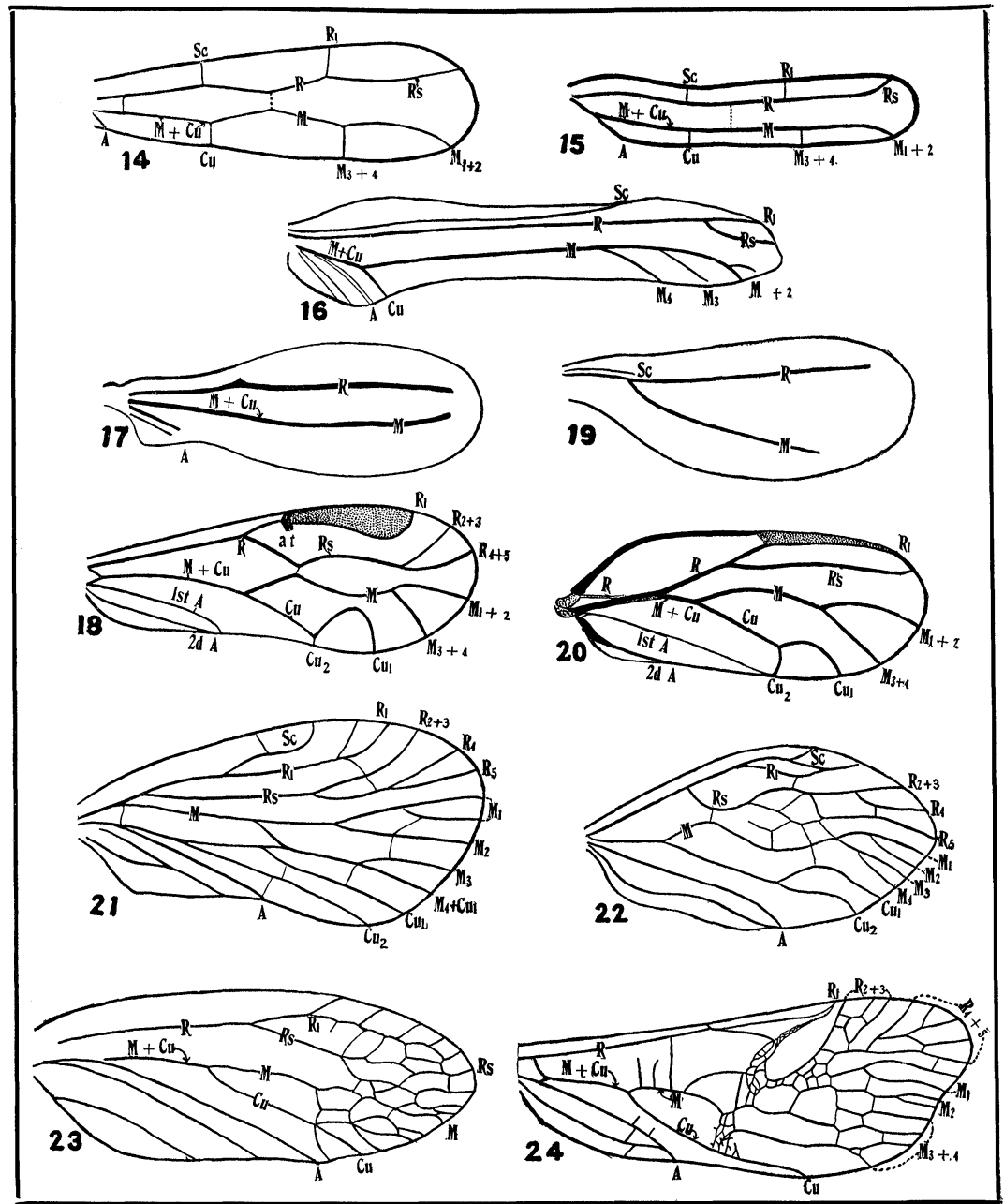

Crampton-Wings of Hemiptera-Homoptera 


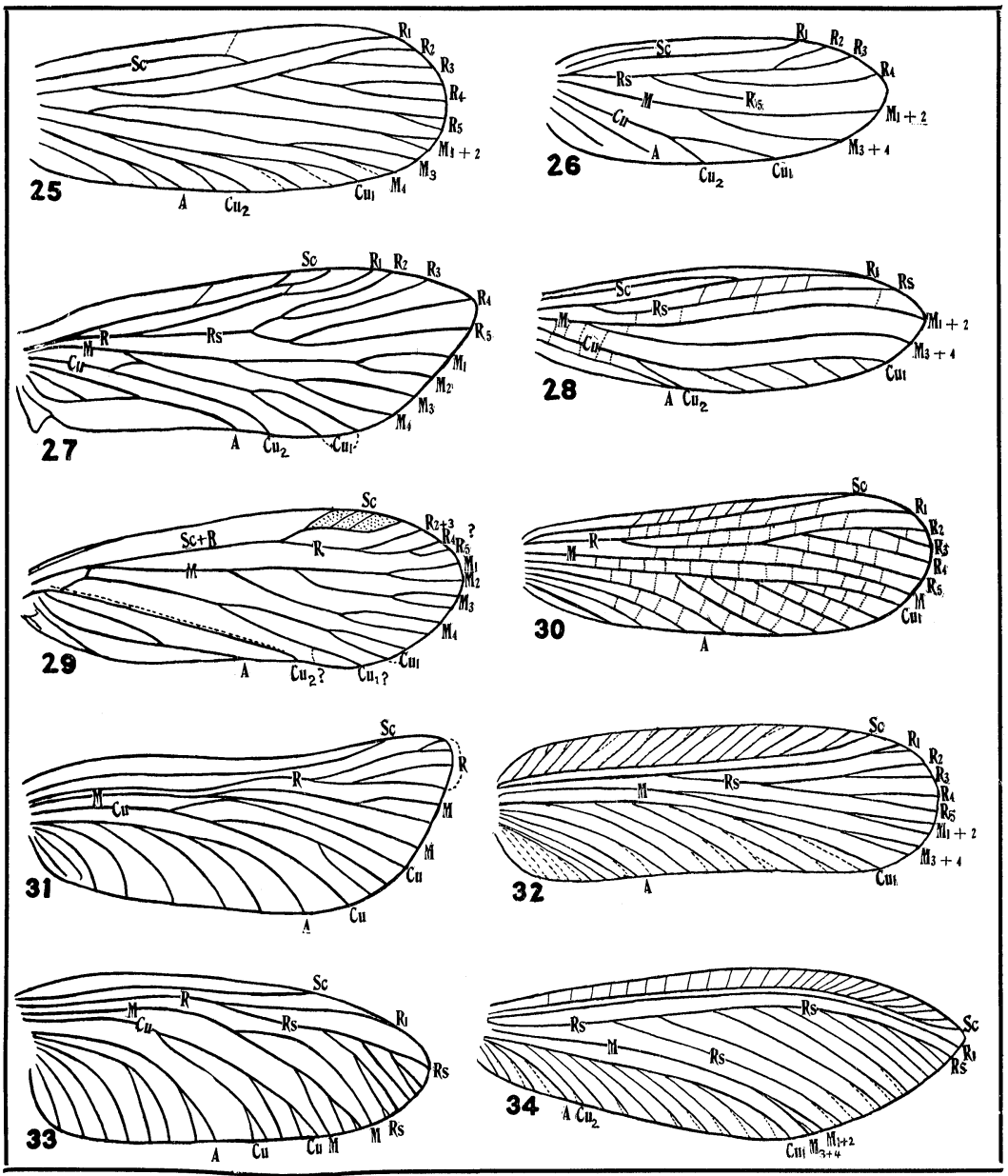

Crampton-Wings of Hemiptera-Homoptera 
Fig. 14.-Thysanopteron Palæothrips fossilis, from Crampton, 1921, after Scudder, 1890.

Fig. 15.-Thysanopteron Aelothrips nasturii, from Crampton, 1921, after Jones, 1912.**

Fig. 16.-Orthopteron Dioconema ornata, redrawn from Handlirsch, 1909.

Fig. 17.-Psocid Embidotroctes paradoxus from Crampton, 1921 after Enderlein.

Fig. 18.-Psocid Hemicaecilius bogotanus from Crampton, 1921, after Enderlein, 1903.

Fig. 19. - Coccid Pseudococcus citri, redrawn from Patch, 1909 .

Fig. 20.-Psyllid Psylla sp., from Crampton, 1921.

Fig. 21.-Fulgorid Bothriocera prosignoretti, redrawn from Metcalf, 1913.

Fig. 22.-Psocid Calopsocus infelix, redrawn from Enderlein, 1903.

Fig. 23.-Cercopid Monecphora bicincta, redrawn from Metcalf, 1917.

Fig. 24.-Psocid Neurosema apicalis, redrawn from Enderlein, 1903.

Fig. 25.-Mixotermitoid Mixotermes lugauensis, redrawn from Handlirsch, 1920.

Fig. 26.- Protorthopteron Delopterum latum, redrawn from Handlirsch, 1920.

Fig. 27.-Trichopteron Rhyacophila redrawn from Betteı, 1913, and Tillyard, 1919.

Fig. 28.-Protorthopteron Probnis speciosa, redrawn from Handlirsch, 1920.

Fig. 29.-Homopteron Dictyophora europoea, redrawn from Handlirsch, 1909.

Fig. 30.-Protorthopteron Gyrophlebia longicollis, redrawn from Handlirsch, 1920.

Fig. 31.-Protohemipteron Eugereon bockingi, redrawn from Handlirrsch, 1920.

Fig. 32.-Protoblattid Protophasma dumasi, redrawn from Handlirsch, 1920.

Fig. 33.-Palæodictyopteron Homoioptera woodwardi, redrawn from Handlirsch, 1920.

Fig. 34.-Neuropteron Nymphites braueri, redrawn from Handlirsch, 1920.

\footnotetext{
*The label was accidentally scraped off from this figure, which is the third from the top in the right hand column of figures.

**The basal portion of this figure was not inked in, (through an oversight) and consequently does not appear in the plate.
} 

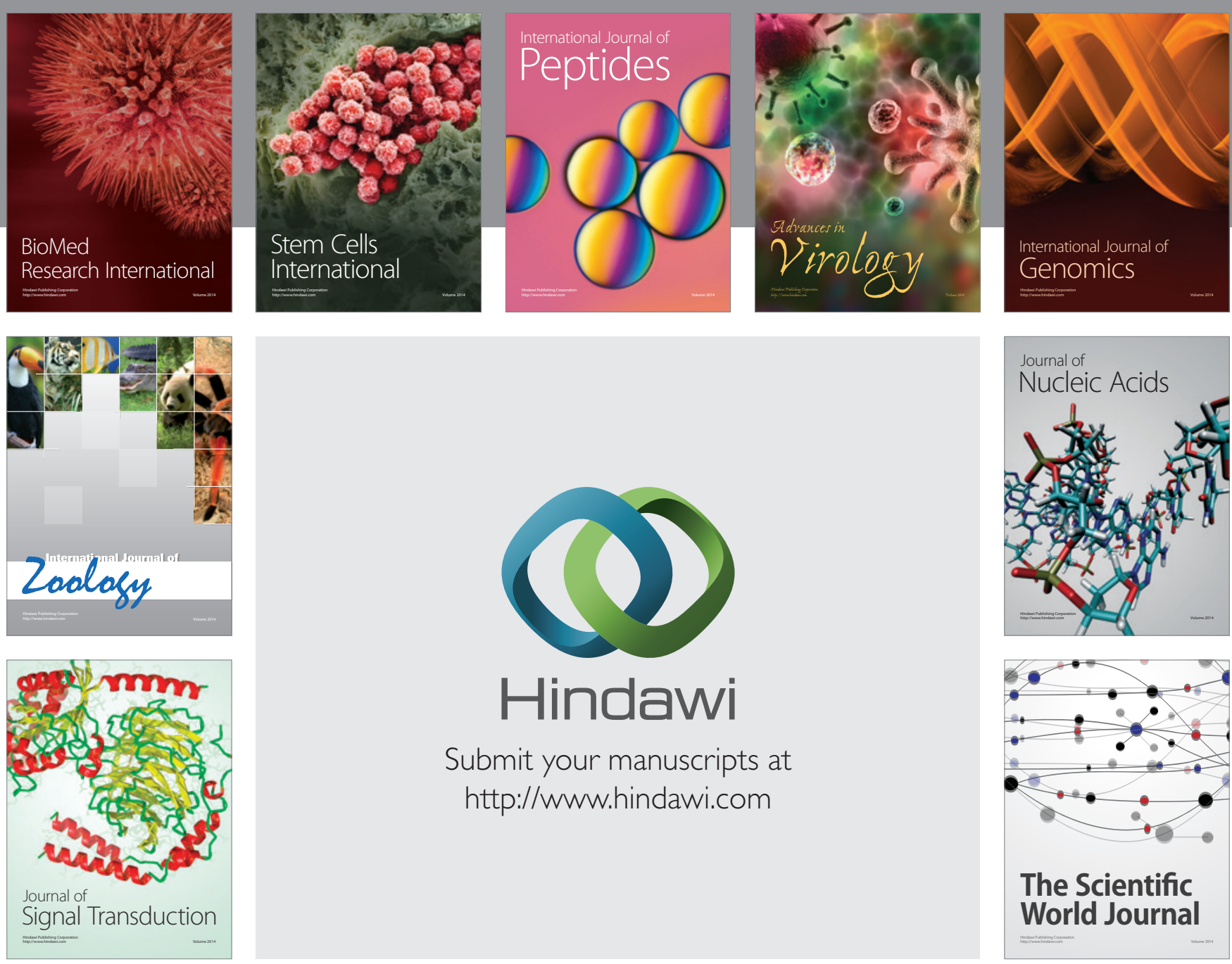

Submit your manuscripts at

http://www.hindawi.com
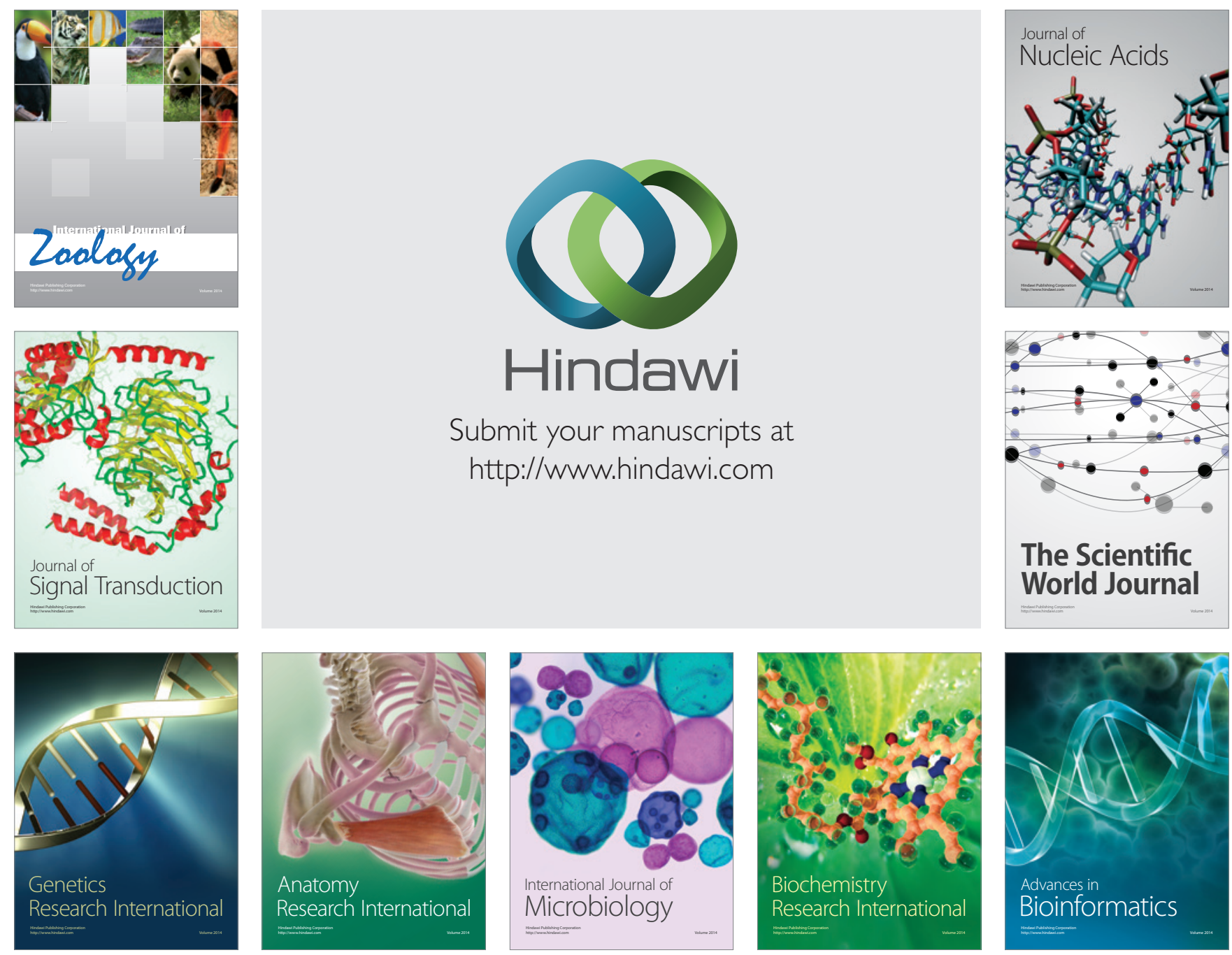

The Scientific World Journal
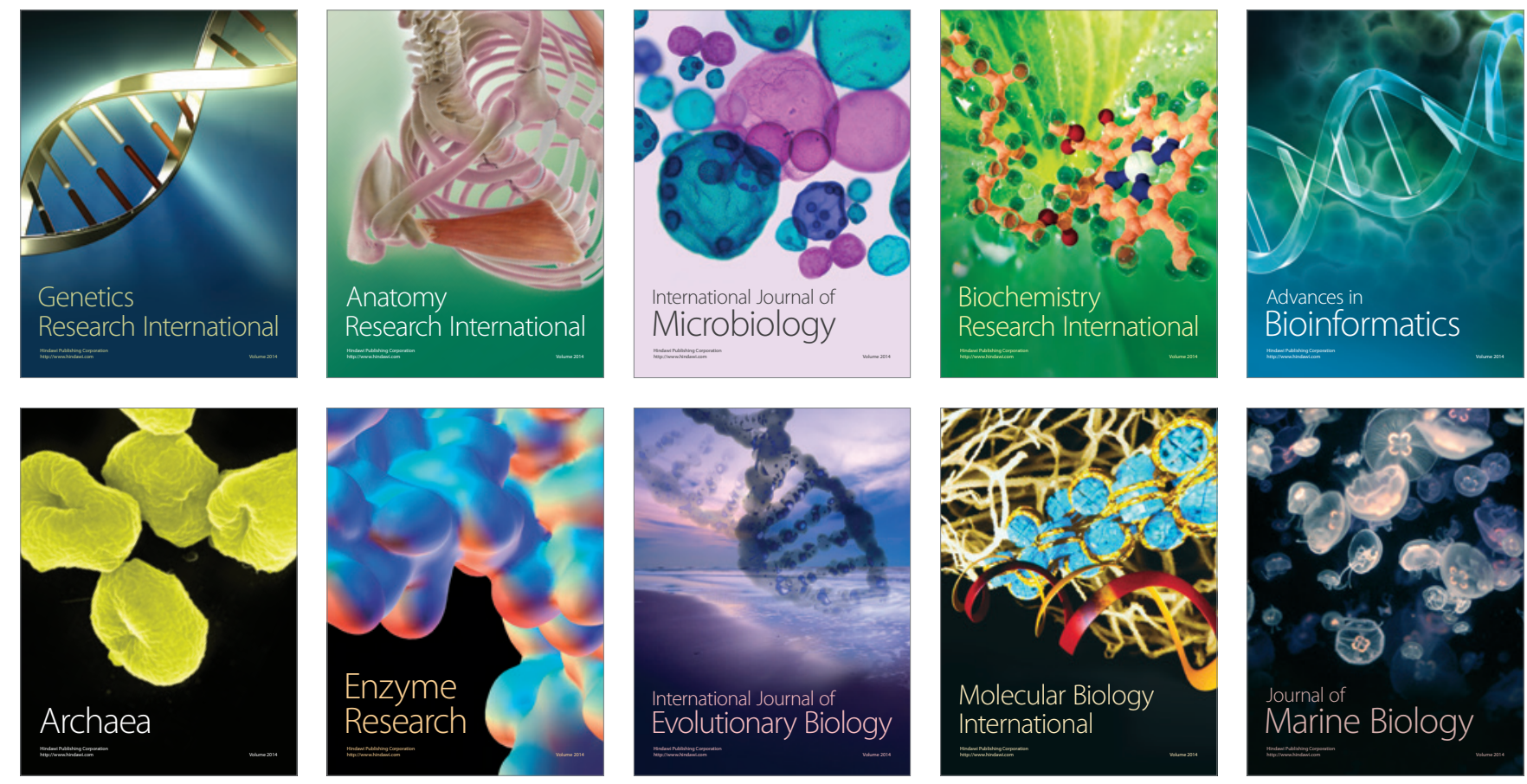